\title{
El liberalismo y la cuestión de los "hombres libres". Un análisis de su problematización en el campo liberal argentino entre 1955 y 1973
}

\section{The Liberalism and the matter of the "free men". An analysis of its problematization in the Argentinean liberal camp between 1955 and 1973}

doi: http://dx.doi.org/10.32870/

espiral.v23i66.5298

\begin{abstract}
Resumen
Este artículo reconstruye la problematización en torno a la "libertad" que se desarrolló en el campo del liberalismo argentino entre 1955 y 1973, a través del análisis de un corpus documental. Se muestra cómo desde diferentes lugares de enunciación la pregunta por la subjetividad requerida para el funcionamiento de la democracia liberal condujo al establecimiento de una serie de oposiciones jerarquizadas. Se concluye que, reforzada por una concepción instrumental de las libertades políticas, la idea de que en la sociedad argentina existía una parte de la población que no era auténticamente libre contribuiría, en esos años, a tornar aceptable la proscripción del peronismo, sin involucrar una contradicción con la democracia.
\end{abstract}

Palabras clave: liberalismo, hombres libres, falta de libertad, democracia, historia.
Victoria Haidar*

\begin{abstract}
Through the analysis of a corpus of documents, we reconstruct the problematization about the "freedom" and "free men" that was developed in the field of argentine liberalism between 1955 and 1973. We show how, from different places of enunciation, the question of subjectivity required for the functioning of liberal democracy led to the establishment of a series of nested oppositions. Reinforced by an instrumental vision of political freedoms, the idea that, in Argentinean society, there was a part of the population that was not truly free, would contribute to render acceptable the proscription of Peronism during those years, without involve contradiction with democracy.
\end{abstract}

Keywords: Liberalism, free men, unfreedom, democracy, history.

- Investigadora asistente del Consejo Nacional de Investigaciones Científicas y Técnicas (CONICET-Argentina) en el Centro de Investigaciones de la Facultad de Derecho y Ciencias Sociales de la Universidad Nacional del Litoral._vhaidar@fcjs.unl.edu.ar 


\section{Introducción}

El propósito de comprender las configuraciones que asumieron, a partir de la década de 1980, los gobiernos y propuestas políticas de la "nueva derecha" en los países de América Latina ha conducido, en los últimos años, a la producción de una multiplicidad de estudios académicos. En Argentina, la inquietud por esclarecer las particularidades de los programas neoliberales que se implementaron en contextos autoritarios ha promovido el desarrollo de un conjunto de investigaciones de inspiración genealógica o inscriptas en el campo de la historia de las ideas. Con diferentes modulaciones, la historia aparece como una herramienta clave para comprender los desarrollos políticos y económicos contemporáneos.

Ciertos periodos históricos que en los estudios sobre el liberalismo argentino no habían sido objeto de un análisis detallado concitan, en la actualidad, un interés creciente, tal como sucede con el lapso que se abre en 1955 con la denominada Revolución Libertadora y se cierra en 1973 con un nuevo Gobierno peronista, el cual revisitamos en este trabajo. Se ha resaltado la importancia de esos años para la formación de una tradición neoliberal en Argentina, tanto en términos de acumulación del saber como de la organización de una serie de redes de sociabilidad (Morresi, 2007, 2008, 2009, 2011; Grondona, 2013). Por otro lado, ese periodo fue estudiado con la finalidad de aprehender el ideario y la autorrepresentación de los intelectuales liberal-conservadores (Vicente, 2012) a la luz de la tradición liberal argentina ${ }^{1}$ y

I. Configurada entre la segunda mitad del siglo XIX y los inicios del siglo XX en respuesta a un conjunto específico de problemas, esa tradición articuló de manera heterodoxa ideas políticas, instituciones y motivos culturales liberales con la preocupación por la construcción de la Nación, la cual incluía la imposición del orden político y el éxito del desarrollo económico. Integrada, entre otros elementos, por un corpus de textos producidos por los intelectuales y políticos 
de las orientaciones que ese filón del liberalismo asumiría durante la última dictadura (1976-1983).

Ampliando y profundizando esos aportes, en este artículo se aborda un corpus de discursos con el propósito de reconstruir la problematización en torno a la "libertad" y a los individuos "libres" que se desarrolló al interior del liberalismo argentino entre 1955 y 1973, en respuesta a las amenazas que, desde esa perspectiva, encarnaba principalmente (aunque no exclusivamente) el peronismo. ${ }^{2}$ En particular, nos proponemos analizar los modos en que una serie de agentes avanzaron en la (re)definición del tipo de subjetividad requerida para el funcionamiento de la democracia liberal, actualizando, por esa vía, los límites de la “comunidad de los libres" (Losurdo, 2005, p. 169) sobre la que se funda el liberalismo.

Con este propósito, construimos y analizamos un corpus de documentos integrado por artículos aparecidos en las revistas Criterio, ${ }^{3}$ Política y Economía ${ }^{4}$ e Ideas sobre la

de la denominada Generación del 37 (Juan B. Alberdi, Domingo F. Sarmiento, Esteban Echeverría, etc.), así como por la Constitución Nacional de 1853, en el pensamiento y en la práctica esa tradición liberal fundacional estuvo atravesada por contradicciones y ambigüedades en torno a las cuestiones del sufragio, la intervención del Estado en la economía y la autoridad estatal (Nallim, 20l4).

2. Desde diferentes posicionamientos, también se percibieron como amenazas el comunismo, las corrientes de la izquierda nacional, el punto de vista del Tercer Mundo y el movimiento de la teología de la liberación.

3. Fundada en 1928 por un grupo de jóvenes católicos, bajo la dirección de Monseñor Franceschi (1932-1957) la revista desplegó una insistente crítica al liberalismo de las clases dirigentes. La experiencia del peronismo, así como las experiencias dictatoriales europeas, atemperaron su discurso. A partir de 1955 se esforzó por articular los principios de la justicia social enunciados por la Iglesia católica con el liberalismo político, incorporando a una generación de jóvenes intelectuales con perspectivas sensibles a la filosofía política no cristiana, la ciencia política, la sociología, etc., para que se ocuparan de los editoriales políticos. Entre dichos intelectuales se encontraban Carlos Floria, Rafael Braun y Natalio Botana (Montserrat, 1999; Heredia, 200I).

4. La revista se creó en 197I por iniciativa de un conjunto de economistas unidos en torno al estudio de Rafael Olarra Jiménez y de Carlos García Martínez. El primero, un abogado especializado en temas financieros, había participado en la creación de la carrera de Economía de la Universidad Católica Argentina en 1958.

Teoría y DEBATE $\&$ No. 66 
Libertad; ${ }^{5}$ diversas contribuciones de ensayistas, periodistas y filósofos que orbitan en torno al Centro de Estudios sobre la Libertad y otros centros de producción y divulgación de ideas liberales $;{ }^{6} \mathrm{y}$, finalmente, una serie trabajos de los economistas Federico Pinedo (1895-1971) ${ }^{7}$ y Álvaro Alsogaray $(1913-2005) .^{8}$

El segundo, graduado de la carrera de Economía de la Universidad de Buenos Aires, dirigía desde fines de la década de 1960 el Centro de Estudios de Política y Economía, un núcleo de pensamiento abocado al diseño de lineamientos de un programa económico. Inspirada por las ideas del emergente "monetarismo", la revista sólo se publicó entre abril de 1971 y marzo de 1973 (Odisio y Rougier, 2014).

5. Ideas sobre la libertad era la publicación periódica del Centro de Estudios sobre la Libertad dedicada principalmente a la divulgación del pensamiento liberal. Se creó en 1957 bajo la dirección del empresario vitivinícola y economista Alberto Benegas Lynch. Autoinscribiéndose en la "línea ortodoxa" que encarnaba la "moderna escuela vienesa" (CDEL 1960, p. 2), el Centro de Estudios sobre la Libertad estaba conectado con varios núcleos transnacionales de producción y difusión de las ideas liberales. Funcionó además como una activa editorial en el marco de la cual se publicaron las conferencias que dieron en Buenos Aires diversos representantes del pensamiento liberal y neoliberal invitados por esa institución, obras de los clásicos del liberalismo y ensayos de filósofos, periodistas e intelectuales nacionales.

6. Entre ellos se encuentran el empresario del sector automotor, periodista y ensayista Manuel Tagle, el almirante retirado Carlos Sánchez Sañudo, el periodista Rodolfo Luque y el filósofo Manuel Río. Todos estos autores publicaron trabajos en la editorial del CDEL, pero, además, se hallaban conectados a otras instituciones que funcionaron como vehículos para la circulación, la difusión y la discusión de ideas liberales, tales como el Instituto Popular de Conferencias del diario La Prensa, el Centro de Estudios San Ignacio, el Rotary Club, el Instituto Naval de Conferencias, el periódico La Prensa y la Academia Nacional de Derecho y Ciencias Sociales de Buenos Aires.

7. Abogado, economista, político. Inició su actividad pública en las primeras décadas del siglo XX en el ámbito del Partido Socialista, al cual se afilió en 19/3. Ministro de Economía en los Gobiernos conservadores durante la década de 1930, se manifestó críticamente respecto del peronismo. Tras la Revolución Libertadora, se inscribió de manera explícita en el espacio del liberal-conservadurismo. Luego de desempeñarse brevemente en el área energética durante la gestión de $A$. Frondizi (1958-1962), en 1962 volvió a ejercer el cargo de ministro de Economía en el Gobierno provisional de José M. Guido (1962-1963), puesto del que se alejó, tras sólo con un mes de gestión, para dedicarse hasta el final de su vida a escribir trabajos centrados en la cuestión económica y en el papel del país en el ámbito internacional (Llamazares Valduvieco, 1995; Vicente, 2013).

8. Ingeniero, economista, político. Álvaro Alsogaray desarrolló una carrera militar de la que se retiró en 1946. Se desempeñó en las áreas de minería e industria 
A través de esta indagación de carácter histórico aspiramos a contribuir a desustancializar los análisis del liberalismo, mostrando que más que fundarse en un conjunto circunscripto de principios morales universales el liberalismo se monta sobre una interrogación acerca de los hombres libres, en el marco de la cual se construyen, de manera simultánea, distintas clases de sujetos. Asimismo, aspiramos a esclarecer algunas de las paradojas que atraviesan al liberalismo en la contemporaneidad, que si por un lado se funda sobre la defensa sempiterna de la libertad y la conducción pacífica de los hombres a través de la autoelección, por otro lado establece restricciones o directamente excluye a ciertos sectores de la población de las posibilidades del autogobierno.

El artículo está organizado de la siguiente manera: tras contextualizar, en el apartado primero, los "problemas prácticos" a los que fuera sensible la reflexión sobre la libertad, nos ocuparemos de mostrar que, para dar respuesta a la pregunta acerca de quiénes eran los "hombres libres", los intelectuales, periodistas, economistas, políticos, activistas y divulgadores que se inscribían en el espacio liberal se inclinaron por un procedimiento indirecto que consistía en investigar la libertad no por sus factores o atributos positivos, sino mediante un análisis minucioso de las situaciones en las que ella estaba excluida. Así, la caracterización de los fenómenos de "masa", que reconstruimos en el apartado segundo, y la focalización, en el plano del "yo", de diferentes fases de la libertad, serían las vías privilegiadas para identi-

durante los Gobiernos militares de la Revolución Libertadora. Entre mediados de 1959 y comienzos de 1961 estuvo a cargo de la cartera de economía en el Gobierno de Frondizi. Asimismo, en 1962 reemplazó a Pinedo en el Ministerio de Economía. En el contexto de la Revolución argentina, el general Onganía lo designó, en 1966, como embajador en Washington, puesto en el que se mantuvo hasta 1968. Durante el periodo que nos ocupa fundó dos partidos políticos de orientación neoliberal: el Cívico Independiente, en 1956, y la Nueva Fuerza, en 1972 (Llamazares Valduvieco, 1995; Morresi, 2008; Haidar, 20I5). 
ficar las carencias, fallas, atrasos, etc., en el desarrollo de la capacidad para el autogobierno, y para decantar, mediante el método de "oposición de contrarios" (Río, 1969, p. 20), la fisonomía del "individuo autónomo". Reforzado y complementado, como veremos en el apartado tercero, con una operación de clasificación y jerarquización de las libertades jurídicas, aquel análisis psicológico-moral de la libertad permitió justificar la proscripción del peronismo y avanzar en la proposición de otras restricciones a los derechos políticos. Finalmente, planteamos algunas conclusiones.

\section{El liberalismo argentino frente al desafío de la "cuestión peronista"}

El periodo que se abrió en la Argentina tras el derrocamiento, por obra de la denominada Revolución Libertadora, del presidente Juan D. Perón (1946-1955) estuvo caracterizado por la alternancia entre Gobiernos civiles y militares de facto y Gobiernos surgidos de elecciones en las que la principal fuerza electoral del país, el peronismo, estuvo proscripta. Entre 1955 y 1973, las Fuerzas Armadas asumieron un rol de "vigilancia" y "veto" sobre el sistema político y el peronismo se expresó, fundamentalmente, a través del movimiento sindical (Scirica, 2008).

El golpe de 1955 fue impulsado por un frente tan amplio como heterogéneo que incluía a los partidos políticos no peronistas, representantes corporativos e intelectuales de las clases medias y las burguesías urbana y rural, y las Fuerzas Armadas. Dicha coalición se mantuvo unida levantando las banderas de la "democracia" y la "libertad" (Cavarozzi, 1983, p. 15), en oposición al carácter totalitario y dictatorial que se atribuía a los Gobiernos peronistas.

Luego del derrocamiento de Perón, esa confluencia no se tradujo en un acuerdo respecto de qué hacer con la "cuestión peronista”. Entre 1955 y 1966 se ensayaron varias fórmulas 
electorales para dar respuesta a la cuestión peronista en el marco del sistema de la democracia liberal con partidos políticos pero con proscripción, ninguna de las cuales alcanzó a consolidarse (Smulovitz, 1991).

Los esfuerzos por dar respuesta a ese desafío se dieron en el marco de un intenso proceso de relectura del peronismo, el cual configuró uno de los rasgos político-culturales del periodo (Terán, 1991). La hipótesis -ampliamente sostenida en el arco antiperonista- de que las masas habían sido víctimas de un "engaño" condujo a los liberales a preguntarse qué parte de la ciudadanía era la "auténticamente libre".

Entre los propósitos que inspiraron la Revolución Libertadora se contaba la reorientación de la economía argentina para acoplarla a los nuevos requerimientos del capitalismo internacional, lo cual significaba, en la práctica, un cambio en la distribución del ingreso a costa de los derechos de los trabajadores (Scirica, 2008) que fue fuertemente resistido.

A la "resistencia peronista" se sumaba, para complicar aún más los proyectos ordenancistas, la conformación, a partir de los años sesenta, de grupos que, al calor de la Revolución cubana y la extensión de los procesos de liberación nacional en diferentes partes del mundo, reivindicaban la lucha armada (James, 2007, p. 14). Desde 1969 en diversas instituciones de la sociedad argentina surgieron sectores contestatarios, gran parte de los cuales se identificaban con el "socialismo nacional" y reivindicaban la "violencia popular" como instrumento legítimo de lucha por el poder (Heredia, 2001, p. 88). Así, al peligro de los sindicatos peronistas vino a agregarse, en la percepción de las élites, aquel de la izquierda radicalizada, el cual era percibido, según los diferentes lugares de enunciación y las coyunturas,

9. Nos referimos a los procesos de lucha que llevaron adelante los trabajadores peronistas, cuya representación tras la proscripción había quedado en manos de los sindicatos (véase: James, 1999). 
como independiente y yuxtapuesto al peronismo o como confundido con este.

Frente al fracaso de los experimentos tendientes a integrar a las masas peronistas y al temor de la expansión comunista en el país, entre 1966 y 1973 se estableció un régimen autocrático de orientación modernizante. Impulsada por un frente de fuerzas amplio y heterogéneo, entre los que se encontraban los liberales, ${ }^{10}$ la denominada "Revolución argentina" se autopresentó como un esfuerzo por transformar y unificar la política "desde arriba”, en un contexto marcado por la crítica generalizada a los partidos políticos y a la democracia electoral (De Riz, 2000, p. 23).

La prohibición de los partidos políticos y la clausura de la actividad del Congreso de la Nación, impuestas por el líder militar del movimiento golpista, el general Juan Carlos Onganía (1966-1970), involucraron la suspensión de los mecanismos de representación democrática. Sin embargo, la utopía tecnocrática que encarnó la Revolución argentina, de reemplazar la "política" por la "administración”, no lograría obturar el proceso de movilización social y política. Ante la imposibilidad de contener protestas que se hacían cada vez más masivas y que habían conducido, en junio de 1970, a la destitución de Onganía, dicho proceso "revolucionario" entró, un año después, en su recta final. Frente a las presiones sociales para que se instrumentara una salida democrática del régimen autoritario, ${ }^{11}$ el general Alejandro A. Lanusse (1971-1973) impulsó un proceso de

10. La inclinación de los liberales hacia una estrategia abiertamente antidemocrática ha tendido a ser explicada a partir de una confluencia de factores: la conciencia creciente acerca de que el peronismo no podía ser erradicado, el temor frente a la estrategia confrontacionista de un sector de este último, así como a la movilización de la izquierda radicalizada y de los sectores intelectuales que participaron en el proceso de modernización social y cultural (Senkman, 200I).

II. Un síntoma de la crisis de la Revolución argentina fue la "Hora del Pueblo": una junta interpartidaria compuesta en noviembre de 1970 por peronistas y radicales, junto a otros partidos menores, exigió públicamente un pronto llamado a elecciones generales con fecha precisa (Nicanoff y Rodríguez, 2008, p. 3II).

\section{8}


"normalización política". En ese marco designó una comisión de prestigiosos juristas para que llevaran adelante un trabajo de reingeniería político-institucional que versaba sobre tres puntos: la legislación sobre partidos políticos, la reforma constitucional y la ley electoral.

La producción de discursos procedentes del campo liberal destinados a dar respuesta al problema de "quiénes eran los libres" reconoció picos de intensidad en las situaciones que, en los Gobiernos de facto que sucedieron en esos años, fueron percibidas como de transición hacia la democracia. En esas instancias resurgían las iniciativas y se suscitaban debates en torno a tópicos tales como el funcionamiento de los partidos políticos, el rol del Congreso, las normas electorales y la reforma de la Constitución. Siempre sensible a las encrucijadas de la coyuntura, esa producción de discurso se haría particularmente dramática cuando, como consecuencia del "plan político" implementado por el general Lanusse, comenzó a insinuarse una salida democrática con plena participación del peronismo.

Hacia 1955, el liberalismo estaba desprovisto, en Argentina, de todo apoyo popular y ocupaba una posición marginal en los debates políticos, económicos e intelectuales. Sin embargo, tanto el dilema del peronismo como todo otro conjunto de factores contribuyeron a imprimirle un tono polémico, un espíritu militante y guerrero. Así, la instalación de la Guerra Fría en América Latina, la aparición del punto de vista del Tercer Mundo, el activismo de la juventud, las reformas y conflictos que atravesaban a la Iglesia católica (Fares, 2012), etc., ofrecieron las condiciones para que los liberales reivindicaran su papel inmemorial de "custodios" e "intérpretes" de la libertad. En ese papel custodial también jugaba un papel destacado la hipótesis neoliberal del "totalitarismo económico" que, a excepción de los intelectuales de la revista Criterio, era ampliamente compartida por los liberales argentinos, y según la cual 
todas las regulaciones de la vida económica conducían, a la postre, al totalitarismo.

Alimentado por el peligro del comunismo, ese papel defensivo concernía a la civilización occidental y cristiana. Gracias a una maniobra de unificación, el liberalismo aparecía encarnando -en contraposición al único y auténtico "Otro", esto es, Oriente- en el "espíritu de Occidente", de la Modernidad y de la cristiandad. En este sentido, para la élite liberal de un país periférico que se pensaba, sin embargo, con categorías eurocéntricas, el desafío de exonerar al peronismo de sus componentes revolucionarios o de desperonizar las masas constituía un modo de estar a la altura con la responsabilidad civilizatoria del hombre blanco y participar de una batalla que tenía alcances transnacionales.

Además del tono "misional" que, en su entrecruzamiento con el cristianismo, asumía para los liberales la defensa de la libertad, es necesario señalar que la resistencia hostil es una "condición necesaria” (De Ruggiero, 1941, p. 359) para el funcionamiento del liberalismo. En la Argentina de los años sesenta, tanto la resistencia peronista como la amenaza del comunismo despertarían ese espíritu de polémica que es consustancial al liberalismo, el cual presupone que la vida de los individuos y de los pueblos se desarrolla mediante la lucha, sublimada en la competencia de mercado. Como señalaron los editorialistas de la revista Criterio durante el tercer Gobierno peronista (1973-1976), en una coyuntura donde la violencia política estaba ampliamente extendida, la libertad "a veces supone lucha, para conservar el conjunto de libertades que existen y tienden a negar determinismos" (Botana, et al., 1973, p. 254).

Esa batalla involucraba la reafirmación de un tipo específico de subjetividad, del individuo racional que, en la perspectiva de Tagle (1970, p. 39) correspondía a la Argentina por su inscripción en el espíritu occidental. Como señalara Pinedo (1956, p. 17), "una democracia compuesta por hom- 
bres libres [...] para proceder como libres todos los días y no sólo el día del comicio" era el antídoto contra el peligro de los despotismos.

La defensa del individuo autónomo se consiguió a partir de una meticulosa operación de diferenciación respecto a toda una serie de situaciones en las que la libertad no estaba suficientemente desarrollada o efectivizada. ${ }^{12}$ En el turbulento mundo de los años sesenta, la adhesión que los sectores populares todavía conservaban por el líder carismático, así como las crecientes escenas de violencia política, parecían revelar la existencia de obstáculos que, en el plano de la subjetividad, entorpecían el proyecto de establecer una democracia liberal y una economía de mercado. Entre esos obstáculos aparecían, en primer lugar, el fenómeno sociológico y psicológico de las “masas", del cual nos ocupamos en el apartado siguiente.

\section{Las masas como figura de la desindividualización}

Organizado de acuerdo a un esquema dicotómico, las masas ocupaban el polo negativo en el repertorio de respuestas que los liberales dieron a la pregunta "¿quiénes son libres?". Recortada sobre la posibilidad de la "dictadura de las mayorías", ${ }^{13}$ la reflexión sobre las masas estaba vertebrada tanto por tópicos procedentes de la tradición liberal argentina como por los trabajos del filósofo español Ortega y Gasset, pero los problemas y énfasis tendían a variar.

I2. En esta dirección, como señala Losurdo (2005), este arte de gobierno funciona demarcando un espacio conformado por los individuos libres e iguales que reúnen las cualidades, virtudes y capacidades para ser gobernados a través de la libertad, del cual se excluye a todos aquellos sujetos que carecen de esos rasgos.

13. Se trataba de un elitismo que no se expresaba en visiones biologicistas, sino que descansaba en preocupaciones de tinte "antitotalitario" según las cuales las mayorías podían conducir a la opresión de las minorías, y sobre la idea de que una ampliación de las esferas de intervención estatal reduce los márgenes de maniobra de las personas (Bohoslavsky y Morresi, 20I I). 
Los discursos de los intelectuales que escribían en la revista católica Criterio giraban en torno al problema de la "democracia de masas", el cual aparecía como un dato de la contemporaneidad que era preciso encauzar de manera más apropiada, pero del que era imposible prescindir. Asumiendo un estilo de escritura académico, los editoriales de la revista se nutrían de los aportes de la sociología política y la ciencia política estadounidense y francesa, sin dejar de hacer referencia, tampoco, a las reflexiones que las masas habían suscitado en las principales figuras políticas e intelectuales de la tradición liberal argentina, ni a los clásicos.

Por su parte, en la producción discursiva de los hombres ligados al Centro de Estudios sobre la Libertad, las observaciones sobre las masas estaban teñidas por el deseo de restauración de una sociedad elitista definitivamente perdida. Si en ambos casos la tradición liberal fundacional tenía una presencia importante, la diferencia se daba en los modos de relectura. Benegas Lynch, Sánchez Sañudo y Tagle, tres figuras de extracción católica inscriptas en el espacio del liberalismo antiperonista más radicalizado, recuperaban de aquel cuerpo de lecturas la idea de que la falta de "cultura política" de los criollos los hacía ineptos para participar en forma inmediata de la cosa pública (Morresi, 2010, p. 106).

En la coyuntura postperonista, algunos de los esquemas establecidos al interior de aquella tradición -como la dicotomía civilización y barbarie procedente del Facundo (1845) de Sarmiento- fueron reutilizados para explicar el presente. Mientras el contraalmirante retirado Sánchez Sañudo (1965, p. 98) sostenía que la opción se daba entre los dos polos del dilema planteado por Sarmiento, en un artículo titulado "Actualidad de la tesis sociológica de Sarmiento", Tagle encontraba en las masas peronistas y en la violencia guerrillera una recreación de las "montoneras" que habían constituido las bases populares de los liderazgos de los caudillos: 
Aunque los rasgos geográficos o étnicos que antaño dieron vida al enfrentamiento se hayan atenuado, la "cosa en si", el contenido ideológico del antagonismo ha permanecido inmutable [...]. ¿Qué son las guerrillas anárquicas sino el espíritu del montonero que renace hiperbolizado? (Tagle, 1972a, p. 37).

Si bien las explicaciones sobre las masas, entendidas como figuras de la desindividualización, tendían a resaltar los motivos culturales, no estaban ausentes, tampoco, las determinaciones raciales. Así, Rodolfo Luque (1963, p. 20), columnista asiduo del diario liberal La Prensa, recuperaba al Sarmiento de Conflicto y armonía de razas en América (1883) con el propósito de sostener la idea de que la incapacidad para la democracia representativa se debía a la mezcla de la raza hispana con la indígena. Para agravar las cosas, tampoco la inmigración había favorecido el desarrollo de la cultura política democrática porque los inmigrantes provenían, en su mayor proporción, de países o regiones donde sus abuelos no habían ejercido el sufragio o lo habían ejercido imperfectamente.

Si bien el abordaje en clave sociológica o histórica de temas políticos era mucho más marginal, también en la revista Política y Economía, que dirigía Rafael Olarra Jiménez, hallamos registro de una interpretación que leía el presente en términos de conflictos "entre culturas" y "entre razas". Así, Cadenas Madariaga (1973) atribuía la incapacidad social y cultural de un sector de la población a la influencia cultural indígena, a la cual situaba en una posición de inferioridad respecto de la cultura europea.

Por su parte, los intelectuales de la revista Criterio, sin abandonar totalmente las interpretaciones dicotómicas de la realidad nacional, se mostraron reacios de las lecturas "reduccionistas" de la tradición liberal. En su lugar, buscaron 
resaltar la existencia de varios liberalismo ${ }^{14}$ y rescataron la confianza que el sector "reformista" de la élite liberal había depositado en el voto popular "razonable".

En el caso de Federico Pinedo y Álvaro Alsogaray, dos economistas que tuvieron una participación activa en la política partidaria, el foco de las preocupaciones no estaba dado por los fenómenos de masa en sí mismos, sino, más bien, por los liderazgos políticos. En el contexto de la crítica a la orientación "tecnocrática" que atribuían a los desarrollismos, Pinedo (1956, p. 43) apelaba al "buen sentido de las masas" y Alsogaray interpelaba al "hombre medio", al "ciudadano corriente", al "hombre común" o al "hombre de trabajo" (Alsogaray, 1960a, p. 4, entre otros textos).

Más allá de estas últimas referencias, y las divergencias en la (re)lectura de la tradición liberal, las masas fueron objeto de valoraciones negativas. Frente a la figura del individuo independiente, equivalían a la desindividualización y, en la lectura católica, a la "despersonalización". ${ }^{15}$ En contraposición al ejercicio del juicio, aparecían como el teatro de las pasiones, los instintos y las sensaciones. Así, en la situación de masa, "el individuo permanece despersonalizado, con predominio de los reflejos condicionados y de los instintos sobre la libertad; individuo 'en estado químicamente puro', hombres-standards, atomizados, con similitudes desesperantes" (Criterio, 1959a, p. 444).

Tagle (1972b, p. 14) apelaba a la voz de una de las figuras destacadas de la tradición liberal, Esteban Echeverría,

14. "Se asume el pasado como un proceso simple, como un western poblado de villanos y de héroes que cambian de lugar según nuestras preferencias ideológicas. Así, el caudillo es nada más que la barbarie y el ilustrado es toda la cultura cívica y política de la Argentina. De esa manera, parece como si hubiera existido un solo liberalismo, y no varios como en realidad fue" (Botana, et al., 1973, pp. 264-265). 15. Así, al criticar la sanción, durante el Gobierno del presidente Frondizi, de la Ley $N^{\circ} 14.455$ de Asociaciones Profesionales, que estableció los aportes obligatorios y el sistema de sindicato único, los editorialistas de Criterio (1959b, p. 645) sostuvieron que esa regulación propendía a la despersonalización y la masificación de la clase obrera.

\section{4}


para ilustrar el conflicto entre la "voluntad" y la "razón” que expresaban dramáticamente las masas:

La razón colectiva sólo es soberana, no la voluntad colectiva. La voluntad es ciega, caprichosa, irracional [...]. La razón examina, pesa y decide [...]. La soberanía del pueblo sólo puede residir en la razón del pueblo, y solamente es llamada a ejercerla la parte sensata y racional de la comunidad social (Tagle, 1972b, p. 14).

El hecho de que la emoción, en lugar de la razón, funcionara, en las situaciones de masa, como la "apasionada rectora de la conducta colectiva" (Floria, 1957, p. 778) explicaba que los hombres fueran "víctimas del engaño de los caciques de la politiquería” (Benegas Lynch, 1965, p. 161). Sin embargo, en la dialéctica líder-masa, el primero no era totalmente libre porque se hallaba sometido a los arrebatos, los caprichos, las oscilaciones de la masa (Floria, 1957, p. 777).

Para la mentalidad liberal, el problema se planteaba porque en las situaciones de masa los hombres no "elegían", sino que "obedecían" (Luque, 1963, p. 22). Entre las escenas de obediencia que desataban la crítica, se encontraba "la sumisión espiritual de ese sector de la juventud comprometido con 'los cambios de estructuras' a la monótona uniformidad de una tendencia a la cual obedece sin saber por qué" (Tagle, 1972a, p. 39). Pero, más allá de la propaganda comunista, las determinaciones que explicaban las situaciones de masa se vinculaban con la operatoria de las necesidades de carácter económico-social.

El deseo de liberarse de la tiranía de las necesidades económicas explicaba en parte, en la opinión de los editorialistas de Criterio, el fenómeno del peronismo, dificultando la integración de las masas en el esquema de la democracia liberal. Los derechos sociales habían reportado para las clases populares una sensación de dignificación, pero esa 
dignificación era falsa porque involucraba la caída en la sumisión espiritual al líder.

La tensión entre liberad y seguridad estructuraba buena parte de las lecturas que se hacían del peronismo desde el espacio liberal, y fue una de las claves de inteligibilidad que se usó para sostener que las "masas peronistas" no eran libres. Sin embargo, las interpretaciones que se hacían de esa tensión no resultaban totalmente equivalentes. Los intelectuales católicos de la revista Criterio no condenaban ese deseo de seguridad en sí mismo, sino el manejo demagógico que se había hecho de él. El hombre-masa anhela seguridad y reclama resultados a los Gobiernos en el desconocimiento de la factibilidad de los mismos y en ausencia de una opinión pública normalmente estructurada que filtre esas demandas, y "esa propensión irresponsable de las masas constituye un factor inspirativo preponderante para demagogos en potencia" (Floria, 1957, p. 777).

Por el contrario, para algunos de los intelectuales próximos al Centro de Estudios sobre la Libertad, esa propensión a la seguridad, si bien condicionada por la sociedad de consumo, encontraba un terreno fértil en los "malos hábitos" de las masas. En la elaboración del filósofo liberal católico Manuel Río (1969, p. 312), bajo el imperio de tal clase de hábitos, los actos conscientes y autónomos se debilitaban al punto que el sujeto degeneraba en un "mero organismo movido por los automatismos no gobernados". Más próximo a las polémicas de la coyuntura, Tagle (1972a, p. 49) era de la opinión de que el problema estaba dado porque las clases populares, incentivadas por mecanismos tales como la venta en cuotas, se habían acostumbrado a vivir por encima de sus posibilidades:

En los hogares con menos recursos son ahora artículos infaltables la radio, el televisor, el lavarropas, el refrigerador y hasta el modesto vehículo de segunda mano. Cobrar el salario y comprobar que instan-

\section{6}


táneamente resulta absorbido por los créditos mensuales es, en el $90 \%$ de los casos, la consecuencia de ese hábito de vida incorregible [...]. El deseo de seguridad prevalece sobre la visión de la libertad (Tagle, 1972a, p. 49).

Asimismo, desde la revista Política y Economía se sugería que, en el marco de los debates en torno a la salida democrática de la Revolución argentina, detrás del proyecto de autorizar la actividad política del peronismo estaba la idea de subvencionar el consumo de ciertos grupos concentrados especialmente en la Gran Buenos Aires, los cuales no estaban en forma "para digerir un régimen de elevada civilización política como es el de compromiso y respeto a las personas que proponen los propiciadores de la llamada 'democracia representativa"'(Villamayor, 1971, p. 19).

Como veremos en el apartado siguiente, esta idea de que los sectores populares no estaban capacitados para el régimen democrático dio lugar a todo un conjunto de reflexiones éticas focalizadas ya no sobre las masas, sino sobre el "yo".

\section{No saben ser libres}

La idea de que las masas habían sido engañadas por Perón condujo a los liberales a cuestionar las libertades que, en apariencia, gozaban. Se hacía necesario, para restaurar la democracia, pasar del plano de las libertades formales, reconocidas por las leyes, y "penetrar en el contenido más sustancial y verdadero" (De Ruggiero, 1941, p. 355) de la libertad. Desde esta perspectiva, el individuo auténticamente libre era el resultado de un cuidadoso y esforzado trabajo interno del "yo" sobre el "yo" que demandaba tiempo, responsabilidad y sacrificios. En palabras de los editorialistas de la revista Criterio (Botana, et al., 1973, p. 254): "la libertad es ascesis, es conquista”. 
Ese trabajo interno presuponía una concepción evolutiva de la libertad, según la cual no había, en sentido estricto, "libertad o falta de libertad", sino, en cada instante "más o menos libertad" (Botana, et al., 1973, p. 254). Se pensaba que los seres humanos transitaban (y un idéntico razonamiento se transponía a los pueblos), a partir de una labor permanente de reforma sobre sí mismos, por distintos niveles o "fases" de libertad que estaban jerarquizados. Esta concepción gradualista procedía de la obra de Guido de Ruggiero (1941), quien en su Historia del liberalismo europeo reconocía la existencia de dos clases de libertades, las cuales se entendían, a la vez, como categorías que describían sistemas históricos y estados psicológicos y morales que coexistían en el presente.

La primera forma de libertad emergente en la historia (siglo XVIII) se denominaba "negativa": suponía la afirmación de una capacidad abstracta y genérica de hacer lo que se quiera; la liberación respecto a cualquier clase de coacción o interferencia exterior. Sobre ese concepto negativo y polémico se había alzado, en el siglo XIX, otro positivo y constructivo, según el cual la libertad es "la capacidad del hombre para determinarse por sí mismo [...] para apartarse, con la espontánea adhesión de la propia conciencia, de las necesidades y de los lazos que la vida práctica le impone" (De Ruggiero, 1941, p. 347).

Esta diferenciación entre dos fases de la libertad, una inferior y otra superior, que se presentaban de manera simultánea en un mismo mundo social funcionaba como un eficaz operador de clasificación y jerarquización social, a partir del cual se podían establecer rangos entre individuos, grupos sociales y naciones, sin con ello sacrificar el presupuesto metafísico de la libertad, entendida como atributo de la "naturaleza humana". En esta dirección, Río (1969, p. 509) distinguía entre la "libertad en su esencia", que suponía exención de toda necesidad que violente, esclavice

\section{8}


y envilezca al hombre, y la "libertad en su plenitud modal". Mientras la primera comprometía a la persona en su totalidad, no era eventual ni estaba condicionada; en cambio, en su plenitud modal, la libertad exigía la intervención de una multiplicidad de factores psicológicos, sociales, etc., que podían darse o no.

Ese efecto de jerarquización y exclusión, que dejaba intocado, no obstante, el núcleo metafísico del liberalismo, explica la calurosa acogida que tuvo la distinción libertad negativa-libertad positiva entre los ensayistas, filósofos, periodistas, economistas, etc., ligados al Centro de Estudios sobre la Libertad, así como su funcionamiento (más sutil y matizado) en los artículos publicados en la revista Criterio. Los autores ligados a ambos espacios de reflexión tendían a colocar a las masas peronistas en la fase de la "libertad negativa" al replantear, en el contexto de los debates en torno a la "cuestión peronista", la pregunta por los hombres libres. Si bien el efecto de jerarquización que producía la distinción entre esas dos formas de libertad tenía una connotación ético-política, en el contexto de la confrontación con el peronismo asumió, también, una connotación de clase. De esta manera, así como no todas las manifestaciones de la libertad tenían el mismo "precio" ni merecían idéntico "respeto" (De Ruggiero, 1941, p. 356), tampoco, en la Argentina de los años sesenta, todas las preferencias político-ideológicas de los ciudadanos, las reivindicaciones de derechos ni las luchas libertarias eran objeto de igual consideración y protección.

La más valiosa, la que generaba respetabilidad, era la libertad moral o espiritual de la que gozaban los hombres que, por haber recibido una educación liberal, formaban parte de la comunidad de los libres y participaban, de pleno derecho, en la vida política. Por el contrario, la liberación que suponía para el aumento de salario era la única cara de la libertad que según su "nivel cultural el obrero estaba 
en condiciones de reconocer" (Uribe, 1955, p. 904). La independencia respecto de la necesidad económica, conseguida por las clases trabajadoras con mediación de las políticas estatales, sólo respondía a un espurio deseo de seguridad, siempre inferior respecto del deseo de libertad. La parte del pueblo que, aun luego de la Revolución argentina, continuaba confiando en Perón "no lo hacía en términos de 'democracia' o de 'libertad', sino de 'seguridad' y satisfacción de sus intereses particulares, antes desatendidos" (Criterio, 1958, p. 845).

La libertad respecto de las necesidades materiales que habían conseguido las clases populares durante el peronismo eran libertades menores, burdas, que sólo comprometían la emancipación material, pero no espiritual. Las críticas se dirigían contra el punto de vista materialista que al reducir la acción humana a la expansión física "reducía la ley humana a la norma de los cuerpos físicos, rebajando sus sujetos a la condición de entes de la Naturaleza" (Río, 1969, p. 213).

Subyacían a esa crítica del materialismo la dicotomía cuerpo-espíritu y la jerarquización del segundo elemento sobre el primero, característica del discurso católico. Floria (1955), uno de los intelectuales de la revista Criterio, recurría a una cita de Esteban Echevarría para exaltar la emancipación moral conseguida a través de la autorreforma del yo: "Echeverría, que la inspiró [a la generación de 1837], fue por ello un libertador del espíritu argentino y, antes, un libertador de su propio espíritu" (p. 650).

Los "menos libres" aparecían frente a los individuos emancipados espiritualmente en una posición de inferioridad que, en algunas interpretaciones, acarreaba indignidad. Es que, tal como señalara Río (1969, p. 23), la necesidad implicaba para el sujeto una marca de vileza. En esta dirección, en las conferencias que solía dar durante su gestión como ministro de Economía en el Gobierno del presidente 
desarrollista Arturo Frondizi, Alsogaray (1960b, p. 14) se dirigía negativamente a los "privilegiados antisociales", que se habían visto beneficiados con las políticas económicas del peronismo y cuya indignidad radicaba en el vínculo de dependencia y subordinación que los ligaba al Estado, cuyos beneficios requerían para generar riqueza.

Tal como se señala en un artículo publicado por uno de los miembros del consejo editorial de Criterio, las clases populares habían hecho, durante el peronismo, una experiencia furiosa, extremadamente rápida de independencia, y se hallaban todavía en esa etapa-inmadura-de rebelión brusca y bastante torpe:

Cada uno ha cobrado conciencia de quién es, y como la ha cobrado bruscamente, llevado por su impulso, la ha cobrado de más [...]. Lo que nos choca y provoca hasta la reacción [...] no [es] la libertad, sino el exceso de su libertad que invade y nos hace perder algo de la nuestra (Uribe, 1955, p. 902).

Al no haber llegado -aún- el estadio que suponía el desarrollo de la personalidad moral, los muchachos peronistas estaban sumidos en un estado de rebeliones espasmódicas, que era característico de la fase negativa, polémica, de la libertad. El mito de Calibán era evocado, también desde una de las editoriales de Criterio, para expresar la situación de ese proceso de humanización/liberación "detenido" como consecuencia de la emancipación acelerada y excesiva:

Que el encantador Próspero lo encadene o desencadene, en ningún caso hallará la felicidad, y vivirá en perpetua rebelión: rebelión contra sus cadenas, contra sus amos cuando se le tiene aherrojado; rebelión contra sí mismo cuando se le libera, porque él es la primera víctima de una libertad que no sabe usar con cordura (Criterio, 1959a, p. 444). 
Al discutir la sanción, durante el Gobierno de Frondizi, de una ley de asociaciones profesionales que, desde la perspectiva de los editorialistas de esa revista, favorecía la conducción tutelar de las clases trabajadoras, estos marcaron significativamente que la actitud de "pura reivindicación" que esgrimían las clases trabajadoras fungía como una confesión de inferioridad, de subordinación. El problema con la clase obrera era que se encontraba todavía en su adolescencia, no había logrado superar el sentimiento de inferioridad para así ascender a la mayoría de edad (Criterio, 1959b, p. 645).

La idea de que las masas no podían distinguir esa instancia positiva, moral y, por lo tanto, superior de la libertad permitía justificar la proscripción del peronismo en los lectores antiperonistas radicalizados (Spinelli, 2005) de De Ruggiero. Pero, asimismo, esa libertad sin responsabilidad caracterizaba la situación moral de los "extremistas que en ausencia de trabas exteriores se sienten inclinados a anarquizar la sociedad" (Tagle, 1965, p. 104). Esa posición sería sugerida, asimismo, por el filósofo Río (1969, p. 506), quien entendía al odio y la destrucción como desvíos de la libertad.

El error en que, en esas miradas, había recaído el peronismo, así como las propuestas que retomaban consignas demagógicas, consistía en pretender que las masas se saltearan el proceso evolutivo interno para arribar arbitrariamente a las funciones superiores, entre las que se ubicaba la elección de los gobernantes. La libertad, recordaba Sánchez Sañudo (1965, p. 100), en una formulación que hablaba del papel que desempeña el miedo en los procedimientos de subjetivación modelados según la ética cristiana, "es un bien que debe ser ganado todos los días" cuyo precio es la "constante vigilancia y lucha".

En esta valorización del propio esfuerzo, que es característica del liberalismo, radicaban algunas de sus tensiones con la democracia. Gracias al proceso de democratización impulsado desde la sanción de la ley Sáenz Peña que con- 
sagró el voto masculino universal, secreto y obligatorio, y de las sucesivas conquistas de derechos sociales, las clases populares gozaban de una multiplicidad de libertades. Pero ese reconocimiento formal contrastaba con las carencias de las que adolecían en el plano de la personalidad. Los votantes de Perón no parecían equipados con las cualidades morales que les permitiesen controlar los "malos hábitos", que, junto al deseo de seguridad, aparecían como los factores psicológicos y morales que favorecían las políticas demagógicas. Les faltaba la educación de sí mismos y la ascética que les permitiese descubrir, corregir y dominar los hábitos malsanos (Río, 1969, p. 313).

Por otra parte, la conquista de las libertades no había sido acompañada de los "saberes" y las "virtudes" requeridas para ejercerlas. El problema estaba dado porque los trabajadores no sabían hacer uso de los derechos. Como se señalara significativamente en uno de los editoriales de la revista Ideas sobre la Libertad: "Para acercarnos al ideal de libertad en el mundo, hacen falta menos reformadores de los demás y más personas dedicadas a reformarse a sí mismas [...]" (CDEL, 1960, p. 3).

En su artículo "Las dos instancias de la libertad", Tagle (1972a) articulaba a De Ruggiero con El miedo a la libertad de Erich Fromm, para sostener que:

No es libre el que disfruta de libertad física, sino el que sabe ser libre. La primera forma es extrínseca al individuo; la segunda plantea la trabajosa exigencia de educar la voluntad y madurar la personalidad. Un hombre sin voluntad para resistir las tentaciones del vicio conviértese en esclavo de su propia debilidad (p. 48).

¿Qué hacer, entonces, con los que "no sabían” ser libres? 


\section{En nombre de la democracia liberal}

En la lectura de los liberales, la falta de desarrollo de la libertad de la que adolecía un sector importante de la población argentina constituía una amenaza para la democracia. Desde las páginas de Ideas sobre la Libertad se sostenía que:

Las instituciones democráticas se han debilitado porque el sistema del sufragio requiere hombres de libre pensamiento que voten como individuos. Una vez que la mentalidad colectiva comienza a debilitar al individualismo, el voto pierde su significación. Poca opción cabe entre una dictadura y un Gobierno democrático elegido por una masa desmoralizada (Smith, 1963, p. 25).

Frente a ese problema, desde todos los sectores se recuperaba la idea de educar al soberano, una de las consignas que vertebraron la tradición liberal argentina. Puesto que la principal amenaza provenía de los comicios, desde los sectores antiperonistas más radicalizados se imaginaron medidas tendientes a limitar el derecho de sufragio. Sánchez Sañudo (1969, p. 84) era de la idea de derogar la regla de la obligatoriedad que se había impuesto con la ley Sáenz Peña en 1912, así como de establecer restricciones fundadas en la edad de los electores y en el grado de escolaridad alcanzado, idea que también compartía el columnista de La Prensa, Rodolfo Luque (1963).

Más allá de esas propuestas, la "proscripción" fue la solución que se impuso a lo largo del periodo 1955-1973. Para los antiperonistas radicales, que encarnaban tanto el Centro de Estudios sobre la Libertad como el núcleo de pensamiento liberal organizado en torno a la revista Política y Economía, esa era la única solución posible, mientras se cumplía el lento y trabajoso proceso de aprendizaje destinado a producir ciudadanos responsables. 
Si bien la restricción de los derechos políticos se fundaba sobre un diagnóstico moral que concernía a la subjetividad del votante peronista que no sabía ser libre y, en situaciones de masa, era objeto de maniobras demagógicas, la delicada economía de libertades y determinaciones que sustenta el edificio liberal hizo necesarias, en el periodo que estamos analizando, argumentaciones complementarias.

La proscripción se apoyó sobre una concepción instrumental de las libertades políticas que las subordinaba a las civiles. Para los intelectuales vinculados al centro de divulgación de ideas liberales creado por Alberto Benegas Lynch, los llamados "derechos de participación" no tenían el mismo valor que los civiles. Mientras estos eran considerados "auténticos" derechos, la valencia de las libertades políticas era relativa y variable. Llegado el caso de una "trágica disyuntiva entre ambos" (Sánchez Sañudo, 1965, p. 42), la solución residía en sacrificar los derechos políticos imponiendo proscripciones cuya aceptabilidad reposaba en la defensa del modo de vida liberal. Dicha postura se expresó en forma categórica cuando, frente a la recuperación del sistema de partidos y de los comicios sin proscripciones dispuesta por el general Lanusse, Benegas Lynch (1973, p. 5) sostuvo que el Estado de derecho no podía someterse a voto.

Junto a estas posturas había otras más pragmáticas y ambiguas. Haciendo suya la opinión del constitucionalista argentino Amancio Alcorta, Pinedo (1956) sostenía que, en caso de conflicto, la prioridad la tenían las libertades civiles, sin que ello significase menospreciar ninguna de las libertades ni decidirse definitivamente por unas u otras. Pero, al mismo tiempo, entendía que los "conservadores" no debían ni podían "mirar con indiferencia la desaparición ni la suspensión por tiempo indefinido de las libertades políticas" (Pinedo, 1956, p. 29). Como ha destacado Martín Vicente (2013), para este autor el peligro residía en los liderazgos políticos y no en las masas. De allí que en el contexto post- 
peronista se inclinara por el restablecimiento paulatino y gradual de la libertad política.

Hacia comienzos de la década de 1960, Alsogaray -un autor que Spinelli (2005, p. 207) coloca, al menos para el periodo 1955-1958, entre los "antiperonistas tolerantes"- se pronunciaba a favor de la integración de las masas peronistas en el sistema político, pero no así de sus representantes. En esa dirección, establecía una distinción entre el "sistema peronista" -que equivalía al "sistema nazi" o al "sistema fascista" - y el "ciudadano peronista" o "experonista", al que homologaba con el ciudadano alemán o italiano de la postguerra:

El "sistema" o "régimen" peronista es contrario a la Constitución Nacional y no puede ser reimplantado en el país. El ciudadano peronista es un ciudadano argentino como cualquier otro; tiene todos los derechos $y$ obligaciones inherentes al mismo, y por lo tanto no puede ser proscripto ni excluido de ningún proceso futuro. Si los ciudadanos experonistas quieren hacer uno o varios partidos conforme a la constitución, a la democracia y a las leyes de la República, nadie debería impedírselo; si quieren utilizar dichos partidos para reimplantar el régimen o sistema peronista, la justicia electoral debe absolutamente negárselo (Alsogaray, 1962, pp. 13-14).

Esa actitud tendencialmente inclusiva de las masas peronistas en el sistema político debe ser matizada con las opiniones favorables a la "democracia fuerte" que manifestara ese mismo autor en trabajos posteriores (Alsogaray, 1968, 1969). Tal modelo de democracia involucraba el refuerzo de los principios de la jerarquía, el orden y la autoridad, así como la imposición de normas que restringieran el número de partidos.

Las intervenciones sobre el Estatuto de los Partidos Políticos, a las que se echó mano entre 1955 y 1973 para resguardar la "comunidad de los libres" de la voluntad de las 
mayorías, hablan de la compleja relación que el liberalismo argentino mantenía con la idea de la soberanía popular, así como de la existencia de disputas en torno de la "democracia" y "lo democrático". ${ }^{16}$

Asociado a la tesis relativa al carácter instrumental de los derechos políticos, aparecía el argumento de una "proscripción democrática”, esto es, de que la prohibición del peronismo perseguía como principal propósito defender la posibilidad de una democracia liberal, un régimen que involucraba el gobierno de las leyes y la representación de las minorías. En nombre de la democracia, cualquier programa partidario que intentara proscribir los derechos individuales debía ser proscrito del escenario político (Benegas Lynch, 1973). El argumento era circular: la proscripción resultaba "democrática" porque permitía preservar la vigencia de la "democracia" (Tagle, 1972b, p. 16).

La noción de "persona" desde la que los intelectuales católicos de la revista Criterio concebían al sujeto de la democracia tensionaba esa concepción compartimentada de la libertad que estaba difundida en el espacio liberal, y según la cual había libertades "principales" y otras "secundarias". Así, en la coyuntura en que se debatía el "plan político" de Lanusse, desde las editoriales de aquella publicación se apoyaba el restablecimiento de los mecanismos de la democracia representativa y la actividad política pública, no sólo del peronismo, sino también del comunismo y el tercermundismo (Botana, et al., 1973, p. 133).

Sin embargo, la posición que los editorialistas mantuvieron respecto al comunismo tuvo sus ambigüedades. $\mathrm{Al}$ comentar el proyecto de una ley "anticomunista" en la

16. La relativización e instrumentalización de los derechos políticos no hacía sino reflejar el "problema" que la democracia representaba para los liberales argentinos que si por una parte manifestaban distanciamientos y críticas respecto de los "derechos de participación", por otra parte estaban convencidos de que el poder político no podía tener otra base de sustentación que la voluntad de las masas (Halperín, 1998). 
coyuntura del onganiato, consideraron la posibilidad de impedir la propaganda comunista utilizando el mismo argumento que otros sectores del liberalismo esgrimían contra el peronismo: era posible introducir controles en nombre de la defensa de "mayores y mejores libertades" (Botana, et al., 1973, p. 255). Reflexionando, en relación al problema práctico del comunismo, acerca de la compleja economía de "libertad-determinación" que estructura el método de gobierno liberal, terminaban apelando a la "prudencia política" del gobernante para dosificar las sujeciones (Botana, et al., 1973, p. 255).

\section{A modo de conclusión}

Desde diversos sectores del espacio del liberalismo argentino se produjeron, entre 1955 y 1973 , de un modo central o marginal y con diverso nivel de intensidad, un conjunto de formulaciones relativas a temas tales como el sufragio, la relación entre las masas y los liderazgos políticos, la cultura política de las masas, etc. Esas enunciaciones, que buscaban dar respuesta a la "cuestión peronista", así como contribuir al debate, más general, acerca del régimen político, configuraron un discurso acerca de los "individuos libres" y de las "libertades" que tuvo densidades teóricas muy distintas.

Articulando perspectivas filosóficas, interpretaciones de la tradición liberal argentina y respuestas pragmáticas a los problemas de la coyuntura política, ese discurso involucró una renovada operación de demarcación entre individuos y grupos "libres" y "no libres", "libres" y "menos libres", que recurrió tanto a la figura de las masas como a un análisis de las libertades, cuyo teatro privilegiado era el "yo". Ambos puntos de vista convergían en la explicación de la disponibilidad de un sector de la población argentina para la obediencia, "ciega", a liderazgos políticos que, como 
el de Juan Domingo Perón, se consideraban demagógicos y dictatoriales.

Así, las situaciones de masas fueron leídas como una suerte de "punto cero" de la libertad, donde, bajo el efecto de una serie de mecanismos psicológicos, el juicio se subordinaba al imperio de las pasiones. La subordinación al líder y la dependencia respecto del Estado encontraban explicación, también, en el insuficiente desarrollo de la libertad en la población argentina. Las masas se encontraban, respecto de las elites, en un estadio de retraso moral. Ello las inclinaba a hacer prevalecer la liberación respecto de las necesidades económicas de la emancipación espiritual, así como a todo un conjunto de manifestaciones reivindicativas, hostiles, que hablaban de la imposibilidad de someterse a la autoridad de la propia ley.

Si bien la clave de la inteligibilidad para avanzar hacia la realización de la utopía liberal de una comunidad de hombres libres que se autogobierna, evitando una nueva "caída" en la servidumbre, se hallaba en el plano de la subjetividad, la idea de que las clases populares no "sabían ser libres" debió reforzarse, con la finalidad de restringir su participación política, por vía de otra operación de demarcación y jerarquización que comprendió a las libertades jurídicas. En consonancia con un modelo de democracia que enfatiza la protección de las minorías, la proscripción del peronismo encontró fundamento en una concepción instrumental, secundaria, de los derechos políticos respecto de los derechos civiles.

Mediante la intervención sobre el Estatuto de los Partidos Políticos se conseguían traducir, en el plano del sistema político, aquellos efectos de jerarquización y subordinación que la demarcación entre "libres" y "menos libres" conducía en el plano social. La inferioridad ética de los hombres de la masa respecto de aquellos de la élite, la marca de vileza que significaba dejarse dominar por los malos hábitos, ser 
incapaces de darse la propia ley, se inscribía, por medio de la proscripción, en la esfera de la política.

Así, el estudio del periodo 1955-1973 permite comprender cómo en Argentina el proceso de reconstrucción y renovación del liberalismo, que culminaría con el ascenso hegemónico del (neo)liberalismo, involucró la reinstalación de la interrogación por los "hombres libres" que atravesaba la tradición liberal. También en un país de la periferia, hacia mediados del siglo XX, como en los países centrales y en otros periodos históricos, la lucha contra aquellos sectores de la población que, en la lectura de las élites, oponían una resistencia hostil a la utopía de la democracia liberal y del mercado dependió de una simultánea identificación de hombres "libres" y "no libres" y, por lo tanto, de una economía compleja de libertades, exclusiones y coerciones. $\varepsilon$

Fecha de recepción: 06 de julio de 2015 Fecha de aceptación: 07 de enero de 2016

Bibliografía

70

Alsogaray, A. (1960a). "Síntesis de la exposición realizada por S. E. el señor ministro de Economía e interino de Trabajo y Seguridad Social, por T. v. Canal 7, Radio Belgrano y su cadena y radio nacional, el día miércoles I 8 de mayo de 1960 a las 21:30 horas", en, Discursos del señor ministro Ing. Álvaro Alsogaray (PP. I - I I). Argentina: Ministerio de Economía. (1960b). "Introducción. 22 de noviembre de 1960", en, Discursos del señor ministro Ing. Álvaro Alsogaray (Pp. I-16). Argentina: Ministerio de Economía. (1962). "Síntesis de la disertación pronunciada por S. E. el señor ministro de Economía el día 3 de octubre de 1962 sobre el tema: definiciones políticas indispensables”, en, Discursos del señor ministro Ing. Álvaro Alsogaray (pp. I-I8). Argentina: Ministerio de Economía. 
(1968). Bases para la acción política futura. Buenos

Bibliografía Aires: Atlántida.

(1969). Política y economía en Latinoamérica. Buenos Aires: Atlántida.

Benegas Lynch, A. (1965). "Colectivismo y libertad”, en H. Hazlitt, C. Sánchez Sañudo, M. Tagle, y A. Benegas Lynch (auts.), El Estado y la libertad (pp. I35- I64). Buenos Aires: Centro de Estudios sobre la Libertad.

(1973). "Corrupción de la democracia y contrabando ideológico". Ideas sobre la Libertad, (30), 3-7.

Bohoslavsky, E., y Morresi, S. (20I I). "Las derechas argentinas en el siglo $X X$ : ensayo sobre su vínculo con la democracia”. Iberoamérica Global, 4(2), I-48.

Botana, N., Braun, R., y Floria, C. (1973). El régimen militar. Buenos Aires: La Bastilla.

Cadenas Madariaga, M. (197I). "Las tres culturas". Política y Economía, (4), 5-8.

Cavarozzi, M. (1983). Autoritarismo y democracia (19551983). Buenos Aires: Centro Editor de América Latina. CDEL (1960). "Por qué somos ortodoxos". Ideas sobre la Libertad, (5), 2-3.

Criterio (1958). "Crisis de dignidad, crisis de responsabilidad". (I320), 843-846. ( (1959a). "El poder y la fuerza". (I334), 443-446. (1959b). "El comunismo y la situación gremial". (I339), 643-645.

De Riz, L. (2000). La política en suspenso (1966//976). Buenos Aires: Paidós.

De Ruggiero, G. (194I). Historia del liberalismo europeo. Pegaso: Madrid.

Fares, C. (20I2). "Apuntes para el debate en torno a los alcances de las derechas y nacionalismos en los sesenta". Cuarto Taller de Discusión las Derechas en el Cono Sur, siglo XX. Los Polvorines: Universidad de General Sarmiento. 
Floria, C. A. (1955). "Proyección histórica de una generación desamparada". Criterio, (1243), 649-650.

(1957). "Opinión pública y demagogia”. Criterio, (I295), 775-778.

Halperín Donghi, T. (1998). "Liberalismo argentino y liberalismo mexicano: dos destinos divergentes”, en, El espejo de la historia: problemas argentinos y perspectivas latinoamericanas (Pp. 143-165). Buenos Aires: Sudamericana.

Grondona, A. L. (20II). "Las voces del desierto. Aportes para una genealogía del neoliberalismo como racionalidad de gobierno en la Argentina (1955-1975)". Revista del CCC, (I3). Recuperado de: http://www.centrocultural. coop/revista/exportarpdf.php?id=27I

Haidar, V. (20I5). “¿Gobernar a través de la libertad? Escrutando las heterogeneidades de la gubernamentalidad neoliberal en los discursos de Álvaro Alsogaray (Argentina 1955- 1973)". A contracorriente, I2(2), I-4I. Recuperado de: http://acontracorriente.chass.ncsu. edu/index.php/acontracorriente/article/view/852/2307 Heredia, M. (200I). "La identificación del enemigo. La ideología liberal conservadora frente a los conflictos sociales y políticas en los años sesenta". Sociohistórica, (8), 83-I 20.

James, D. (2007). “Introducción”, en D. James (dir.), Violencia, proscripción y autoritarismo. Nueva Historia Argentina (pp. II-I5). Buenos Aires: Sudamericana.

Llamazares Valduvieco, I. (1995). "Las transformaciones del discurso liberal-conservador en la Argentina contemporánea: un examen del pensamiento político de Federico Pinedo y Álvaro Alsogaray”. América Latina Hoy, (I2), I43-I54.

Losurdo, D. (2005). La contrahistoria del liberalismo. España: Viejo Topo.

Luque, R. (1963). "De la montonera al sufragio universal”. Ideas sobre la Libertad, (I3), I4-24. 
Montserrat, M. (1999). "El orden y la libertad. Una historia Bibliografía intelectual de Criterio (1928-1968)", en N. Girbal de Blacha, y D. Quattrocchi-Woison (comps.), Cuando opinar es actuar: revistas argentinas del siglo XX (Pp. I5I191). Buenos Aires: Academia Nacional de Historia.

Morresi, S. (2007). "¿Más allá del neoliberalismo? Estado y neoliberalismo en los años noventa", en E. Rinesi, G. Nardacchione, y J. Vomaro (comps.), Las lentes de Víctor Hugo. Transformaciones políticas y desafios teóricos en la Argentina reciente (PP. II7-I50). Buenos Aires: UNGS-Prometeo.

(2008). La nueva derecha argentina. Buenos Aires: Biblioteca Nacional.

(2009). "Neoliberales antes del neoliberalismo", en G. Soprano, y S. Frederic (eds.), Política y variaciones de escalas en el análisis de la Argentina (pp. 32 I-350). Buenos Aires: UNGS-Prometeo.

(2010). "El liberalismo conservador y la ideología del Proceso de Reorganización Nacional”. Sociohistórica, (27), I03-135.

(20II). "Las raíces del neoliberalismo argentino (1930-1985)”, en M. A. Rossi, y A. López (comps.), Crisis y metamorfosis del Estado argentino: el paradigma neoliberal en los noventa (pp. 47-70). Buenos Aires: Luxemburg. Nállim, J. (2014). Trasformación y crisis del liberalismo. Su desarrollo en la Argentina en el periodo 1930-1955. Buenos Aires: Gedisa.

Nicanoff, S., y Rodríguez, S. (2008). "La 'Revolución Argentina' y la crisis de la sociedad posperonista (1966-1973)", en S. de Luque, A. Filadoro, A. Giuliani, et al. (auts.), Historia Argentina contemporánea (pp. 25I-3 I8). Buenos Aires: Dialektik.

Odisio, J., y Rougier, M. (20I4). "Los críticos de la industrialización. Ideas y propuestas de Política y Economía a principios de los setenta”, en M. Rougier, E. Gálvez, 
P. Jerez, et al. (auts.), Perspectivas sobre la industria 2. Buenos Aires: Facultad de Ciencias Económicas.

Pinedo, F. (1956). El fatal estatismo. Buenos Aires: Guillermo Kraft.

Río, M. (I969). La libertad. Elección-Amor-Creación. Buenos Aires: Abeledo Perrot.

Rose, N. (1996). “Governing 'Advanced' Liberal Democracies”, en A. Barry, T. Osborne, y N. Rose (eds.), Foucault and Political Reason: Liberalism, Neo-liberalism and Rationalities of Government (pp. 37-64). Londres: University College London Press.

Sánchez Sañudo, C. (1965). "La encrucijada de la libertad", en H. Hazlitt, C. Sánchez Sañudo, M. Tagle, y A. Benegas Lynch (auts.), El Estado y la libertad (pp. $4 \mathrm{I}$ - I00). Buenos Aires: Centro de Estudios sobre la Libertad.

(1969). "La planificación en las Fuerzas Armadas y su imposibilidad en la sociedad”, en S. Héctor Huici, C. Sánchez Sañudo, y A. Benegas Lynch (eds.), Derecho, planificación y libertad (pp. 33-9I). Buenos Aires: Centro de Estudios sobre la Libertad.

Scirica, E. (2008). "Proscripción, modernización capitalista y crisis”, en S. de Luque, A. Filadoro, A. Giuliani, et al. (auts.), Historia argentina contemporánea (pp. 213-249). Buenos Aires: Dialektik.

Senkman, L. (200I). "La derecha y los gobiernos civiles, 1955-1976”, en D. Rock, S. Mc Gee, M. E. Rapaol, et al. (auts.), La derecha argentina. Nacionalistas, neoliberales, militares y clericales (pp. 277-319). Buenos Aires: Javier Vergara Editor.

Smith, H. (1963). "La crisis argentina”. Ideas sobre la Libertad, (I4), I7-29.

Smulovitz, C. (1991). "En busca de la fórmula perdida: Argentina 1955-1966”. Desarrollo Económico, 3I(I2I), II3-124. 
Spinelli, M. E. (2005). Los vencedores vencidos. El antiperonismo Bibliografía y la "'Revolución Libertadora". Buenos Aires: Biblos.

Tagle, M. (1965). "Una concepción equivocada de la democracia”, en H. Hazlitt, C. Sánchez Sañudo, M. Tagle, y A. Benegas Lynch (auts.), El Estado y la libertad (pp. I0I-134). Buenos Aires: Centro de Estudios sobre la Libertad.

(1970). Nuestra civilización occidental y cristiana. Buenos Aires: Emecé.

(1972a). ¿Hacia dónde va la democracia en América Latina? Buenos Aires: Centro de Estudio sobre la Libertad.

(1972b). "Los dos significados de la palabra proscripción”. Ideas sobre la Libertad, (28), I2-16.

Terán, O. (1991). Nuestros años sesentas. Buenos Aires: Punto Sur.

Uribe, B. (1955). "El procedimiento democrático". Criterio, (I249-1250), 902-905.

Vicente, M. (20I2). "Entre el liberalismo y el republicanismo en las derechas de la Argentina (1955-1983): ¿cómo construir una genealogía del ideario liberal-conservador desde sus intelectuales?", en E. Bohoslavsky, y O. Echeverría (comps.), Las derechas en el Cono Sur, Siglo XX. Actas del Segundo Taller de Discusión. Tandil: Secretaría de Investigación FCH-IEHS/UNICEN.

(20I3). "Los furores de una demagogia destructora: sociedad de masas, liderazgo político y Estado en la trayectoria político-intelectual de Federico Pinedo". Nuevo Mundo Mundos Nuevos. Recuperado de: http:// nuevomundo.revues.org/65654. doi: 10.4000/nuevomundo.65654 